\title{
A Laser-Induced Heat Flux Technique for Convective Heat Transfer Measurements in High Speed Flows
}

\author{
A.R. Porro
}

Lewis Research Center

Cleveland, Ohio

T.G. Keith, Jr.

Ohio Aerospace Institute

Brook Park, Ohio

and

University of Toledo

Toledo, Ohio

and

W.R. Hingst

Lewis Research Center

Cleveland, Ohio

Prepared for the

14th International Congress on Instrumentation in Aerospace Simulation Facilities sponsored by the IEEE Aerospace and Electronics Systems Society

Rockville, Maryland, October 27-31, 1991 


\section{A Laser-Induced Heat Flux Technique for Convective Heat Transfer Measurements in High Speed Flows}

\author{
A.R. Porro \\ National Aeronautics and Space Administration \\ Lewis Research Center \\ Cleveland, Ohio 44135
}

\author{
T.G. Keith, Jr. \\ Ohio Aerospace Institute \\ Brook Park, Ohio 44142 \\ and \\ University of Toledo \\ Toledo, Ohio 43606
}

\author{
W.R. Hingst
}

National Aeronautics and Space Administration

Lewis Research Center

Cleveland, Ohio 44135

\begin{abstract}
In this study, a technique is developed to measure the local convective heat transfer coefficient on a model surface in a supersonic flowfield. The technique uses a laser to apply a discrete local heat flux at the model test surface, and an infrared camera system determines the local temperature distribution due to the heating. From this temperature distribution and an analysis of the heating process, a local convective heat transfer coefficient is determined.

The technique was used to measure the local surface convective heat transfer coefficient distribution on a flat plate at nominal Mach numbers of 2.5, 3.0, 3.5, and 4.0. The flat plate boundary layer initially was laminar and became transitional in the measurement region. The experimentally-determined convective heat transfer coefficients were generally higher than the theoretical predictions for flat plate laminar boundary layers. However, the results indicate that this non-intrusive optical measurement technique has the potential to measure surface convective heat transfer coefficients in high speed flowfields.
\end{abstract}

\section{Nomenclature}

A heated area due to applied heat flux, $2 \pi r \delta$

h convective heat transfer coefficient $\left(W / m^{2} K\right)$

$I_{0} \quad$ modified Bessel function of the first kind of order 0

$K_{o} \quad$ modified Bessel function of the second kind of order 0

$K_{1} \quad$ modified Bessel function of the second kind of order 1

k thermal conductivity of gel-coat resin (0.519 $\left.W / m^{2} K\right)$

L flat plate model length, $40.64 \mathrm{~cm}$

M Mach number

$\mathrm{P} \quad$ static pressure $(\mathrm{Pa})$

$P_{0} \quad$ total or pitot pressure $(\mathrm{Pa})$

$P_{r} \quad$ reflected laser power (W)

$P_{t} \quad$ transmitted source laser power (W)

Pr Prandtl number

q heat transfer rate (W)

Re Reynolds number r radial distance of heated area element

$r_{c} \quad$ wall temperature recovery factor

$r_{s} \quad$ radius of applied laser source, $0.65 \mathrm{~mm}$

$\mathrm{S} \quad$ flat plate model width, $30.48 \mathrm{~cm}$

St Stanton number

$\mathrm{T} \quad$ local wall temperature $(\mathrm{K})$

$T_{o} \quad$ total temperature $(\mathrm{K})$

$T_{s} \quad$ static temperature (K)

$\mathrm{x}$ axial (streamwise) coordinate relative to leading edge of the flat plate model

z transverse (spanwise) coordinate relative to model centerline

$\delta \quad$ nominal thickness of gel-coat resin, $1 \mathrm{~mm}$

$\theta \quad$ reference temperature, $T-T_{\text {aw }}$

\section{Subscripts}

$\begin{array}{ll}\text { aw } & \text { adiabatic wall condition } \\ \mathrm{o} & \text { total or plenum conditions } \\ \mathrm{r} & \text { radial position }\end{array}$

\section{Introduction}

Current efforts in aerospace research and development are aimed towards high speed flight. The National Aerospace Plane Program (NASP) is developing an aircraft that can take off from a conventional runway and accelerate to a low earth orbit trajectory. This aircraft will cover the speed regime from Mach 0 to 25. Also, NASA is initiating a research program to develop basic technology needed for a High Speed Civil Transport (HSCT). The HSCT is projected to have a top speed of Mach 5.

Associated with high Mach number flight is increased aerodynamic heating and the need for an aircraft designer to foresee potential heating problem areas while the aircraft concept is in the design stage. In order to accomplish this, reliable heat transfer data must be obtained through basic wind tunnel experiments that consider aerothermal problems such as shock/boundary layer interactions and stagnation point heat transfer.

The primary objective of this investigation is to develop a practical instrumentation system capable of high 
resolution surface convective heat transfer measurements in complex, three-dimensional high speed flows. Ideally, such a technique should be non-intrusive so that the flowfield surrounding a model is not disturbed at all by the measurement apparatus. Also, it is desirable for the measurements to be made efficiently at multiple locations on a model surface during the same test run. Conventional surface convective heat transfer measurement techniques such as heat flux gauges and joule-heated metallic strips typically are permanently mounted on a model surface which fixes the measurement regions of a model.

In order to satisfy these objectives, a conceptual formulation of an instrumentation system must be conducted. Next, a feasibility study is made to determine whether the concept considered is practical and can be easily implemented. The system is then designed and benchmarked in a realistic situation.

The present investigation, as with Heath et al. [1], uses infrared thermography to monitor surface model temperatures with an applied heat flux due to a laser heating source. However, while Heath et al. induces a heat flux along a two dimensional line on an airfoil surface and obtains a convective heat transfer coefficient relative to the free convection case, this study induces a heat flux at a small area element and attempts to calculate an absolute local convective heat transfer coefficient.

The concept uses an argon-ion laser to induce a local heat flux at a model surface in a wind tunnel. A commercially available infrared camera system measures the surface temperature at the location where the flux is applied. With a known applied heat flux and model surface temperature, the local convective heat transfer coefficient is calculated. The measurement system is mounted on a three axis positioning table which allows efficient mapping of the local convective heat transfer coefficient over an entire model surface. The optical/infrared sensing nature of this measurement system satisfies the non-intrusive requirement in the respect that there are no probes or surface mounted gauges immersed in the flowfield.

However, there is the possibility that applying a local heat flux at the flow surface will disturb the naturallyoccurring thermal boundary layer. If this local heating becomes significant, an unheated length boundary condition is imposed on the surface, and the resulting experimental heat transfer coefficients obtained by using this technique will be higher than for the constant temperature or constant heat flux boundary condition cases.

The experiment chosen to assess the performance of this technique, called the Laser-Induced Heat Flux (LIHF) technique, involves supersonic flow over a flat plate in which boundary layer transition from laminar to turbulent flow occurred. The test was conducted in the NASA Lewis Research Center 1 x 1 foot supersonic wind tunnel (SWT). Four test conditions were chosen at nominal Mach numbers of 2.5, 3.0, 3.5, and 4.0. The actual Mach numbers and test conditions are summarized in Table 1.

\section{Measurement Technique}

The Laser-Induced Heat Flux (LIHF) technique determines a local convective heat transfer coefficient by monitoring the temperature distribution on a model surface with an infrared camera system as it is heated by a laser beam. In order to successfully make a measurement, the applied laser power must be known, along with the size and temperature distribution of the heated area. The infrared camera system monitors both the surface temperature and heated area size, while a sub-system must be developed to monitor and control the applied laser power. The LIHF system design used in this investigation is shown in Fig. 1. The main components of the system are essentially divided into two groups: the transmitting section, which controls and applies the laser heat flux, and the receiving section, which monitors the heating at the model surface.

Table 1. Experimental Conditions

\begin{tabular}{|c|c|c|c|c|c|c|c|}
\hline $\begin{array}{c}\text { Nominal } \\
\text { Mach } \\
\text { Number }\end{array}$ & $\begin{array}{c}\text { Actual } \\
\text { Mach } \\
\text { Number }\end{array}$ & $\begin{array}{c}\text { Tunnel } \\
\text { Total } \\
\text { Pressure } \\
(\mathrm{kPa})\end{array}$ & $\begin{array}{c}\text { Tunnel } \\
\text { Static } \\
\text { Pressure } \\
(\mathrm{kPa})\end{array}$ & $\begin{array}{c}\text { Tunnel } \\
\text { Total Tem- } \\
\text { perature } \\
(\mathrm{K})\end{array}$ & $\begin{array}{c}\text { Unit } \\
\text { Reynolds } \\
\text { No. } \\
\left(\times 10^{-6} \cdot \mathrm{m}\right)\end{array}$ & $\begin{array}{c}\text { Applied } \\
\text { Heat Flux } \\
(\mathrm{mW})\end{array}$ & $\begin{array}{c}\text { Spanwise } \\
\text { Survey } \\
\text { Location } \\
(\mathrm{z} / \mathrm{S})\end{array}$ \\
\hline 2.5 & 2.48 & 103.43 & 6.27 & 294 & 10.08 & 75 & 0.0777 \\
\hline 3.0 & 2.93 & 120.57 & 3.65 & 298 & 9.21 & 75 & -0.040 \\
\hline 3.5 & 3.48 & 241.05 & 3.24 & 298 & 14.33 & 85 & 0.0732 \\
\hline 4.0 & 3.95 & 206.62 & 1.45 & 294 & 9.82 & 125 & 0.0622 \\
\hline 4.0 & 3.95 & 206.62 & 1.45 & 294 & 9.82 & 130 & 0.0622 \\
\hline
\end{tabular}




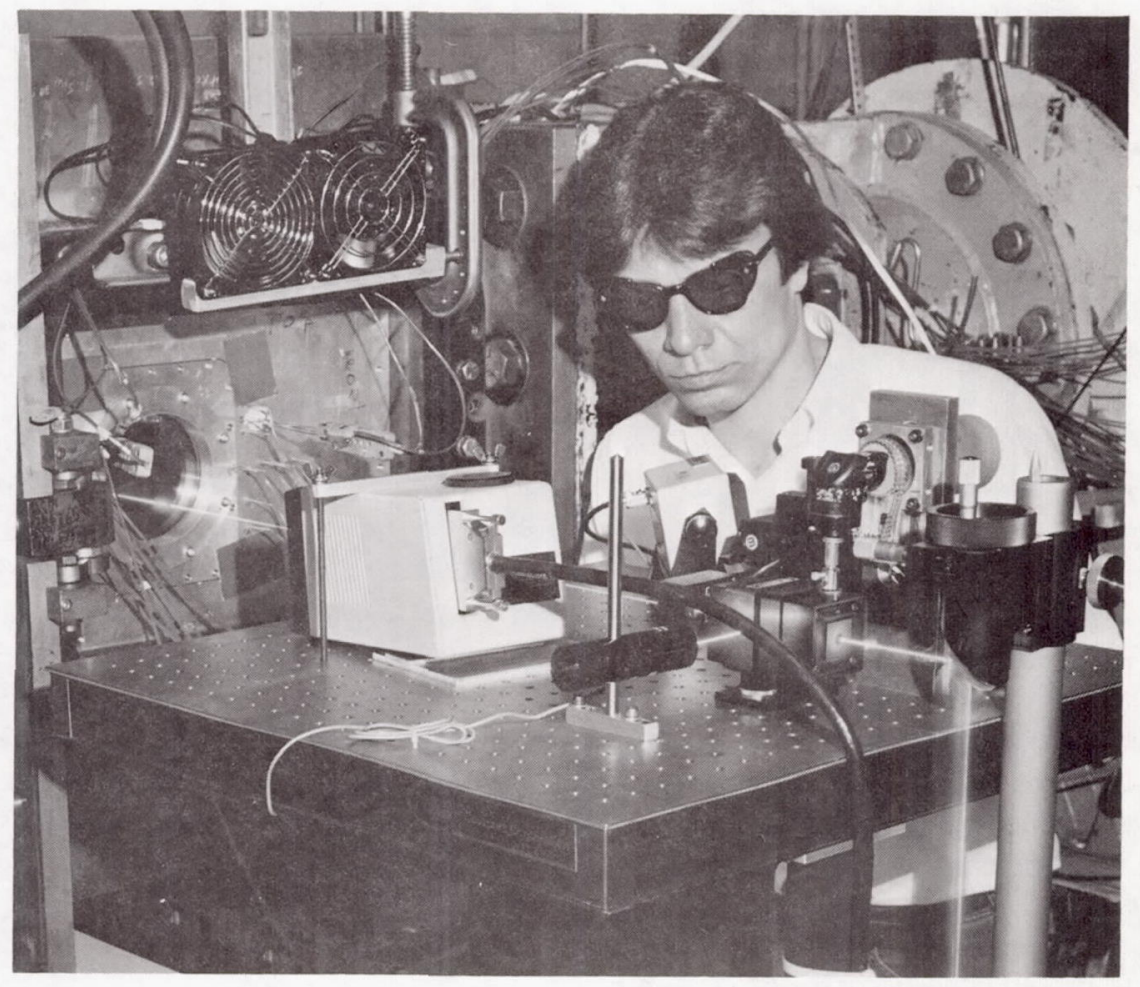

Figure 1. Photograph of LIHF System

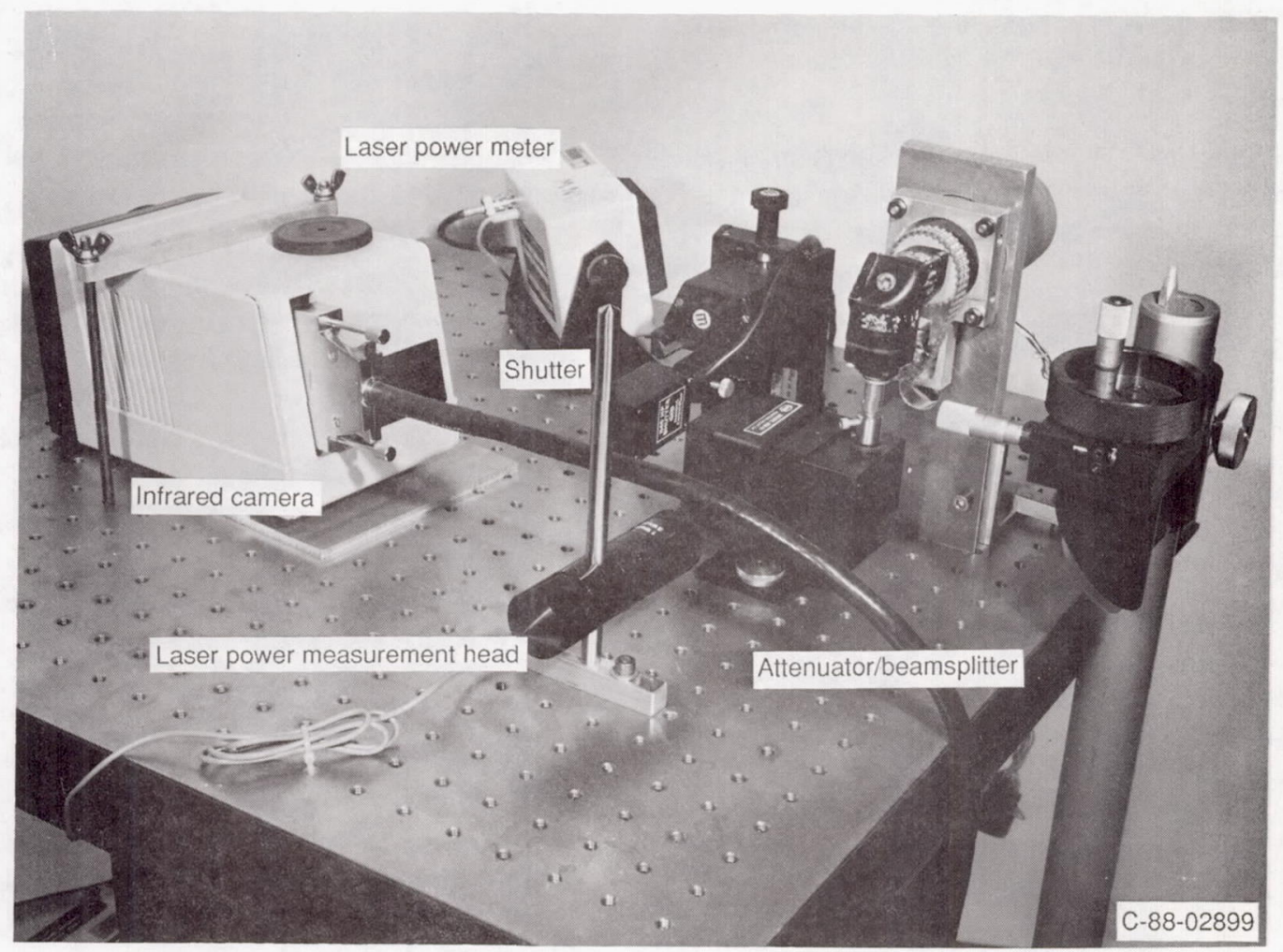

Figure 2. Close-up View of LIHF System 
The transmitting section is patterned after an optical system developed by Stinebring [2] to measure skin friction in fluid flows. It consists of an argon-ion laser which supplies the required heat flux (laser power per unit area), an attenuator/beamsplitter to control the amount of laser power directed to the model surface, an electronic shutter to control the time duration of the applied power, and a laser power meter which monitors the power of the reflected beam from the beamsplitter. An overall view of the LIHF system is shown in Fig. 1, and a detailed view of the transmitting optics is shown in Fig. 2.

When the system is in operation, the argon-ion laser is tuned to $514.5 \mathrm{~nm}$, the green light wavelength. It operates in a continuous mode so that a stable power source is supplied to the transmitting optics. The attenuator/beamsplitter is used to control the source laser power used in the experiment. As the name implies, this unit splits the incoming laser beam into two perpendicular beams. Essentially, the beamsplitter transmits a portion of the incident beam and reflects the rest. The attenuator, which is adjustable, varies the power level between the two beams. The transmitted beam is used for the experiment, while the reflected beam's energy is monitored by a power meter. This technique allows for a calibration of the transmitted power applied to the model surface. After the transmitted beam exits the attenuator/beamsplitter assembly, it enters a high power electronic shutter assembly whose function is to control the time duration of the power applied at the model test surface.

The receiving section of the LIHF system is a commercially-available infrared camera system, an Inframetrics Model 600 Imaging Radiometer. It is used to determine the temperature distribution at the portion of the model surface that is heated by the incident laser beam. The infrared camera system basically is an imaging radiometer that does not measure temperature directly. A single infrared radiation detector scans the camera viewing area by the use of high-speed electromechanical galvanometers. Based on these radiation levels, the system is able to calculate a temperature utilizing a calibration stored in a microprocessor. However, this calibration incorporates certain assumptions about the environment where the camera system is located, so the resulting calculated temperatures are incorrect when the system is used in a non-standard situation. The system used in this investigation monitors radiation emitted in the $8-14 \mu \mathrm{m}$ wavelength range. A detailed description of the system used in this investigation can be found in Ref. [3]. Since the area heated by the laser beam was small, typically on the order of 10 $\mathrm{mm}$, a zoom feature on the camera system allowed detailed observation of the heated area on the model.

The infrared camera system incorporates data scan conversion circuitry to convert the acquired infrared thermal images into a TV compatible output signal. This allows the data to be viewed as it is acquired on a television monitor and simultaneously be recorded by a video cassette recorder (VCR) in a standard format. Detailed data reduction is performed off-line with a PC based data reduction system using these video tapes. The infrared camera system manufacturer developed the data reduction system.

The LIHF system installed in the NASA Lewis $1 \mathrm{x} 1$ SWT is shown in Fig. 1. The laser is mounted below the wind tunnel test section on a remotely-controlled three axis positioning system. Mirrors are used to direct the laser beam to the transmitting optics which are mounted above the laser on an optical breadboard with the infrared camera. The use of the positioning system allows an efficient method of remotely moving the measurement location during an experiment. A Cleartran grade zinc sulfide window provides optical access to the wind tunnel model. This particular grade of zinc sulfide transmits efficiently in the 0.4 to $12.0 \mu \mathrm{m}$ wavelength range.

\section{Experimental Hardware}

Since the objective of this investigation was to develop the LIHF system to measure the convective heat transfer coefficient in high speed compressible flows, an experiment was formulated to assess the performance of the LIHF system. The experiment chosen was supersonic flow over a flat plate, in which the boundary layer transitioned from laminar to turbulent flow. This experiment was conducted in the NASA Lewis $1 \times 1$ foot SWT.

The NASA Lewis $1 \times 1$ foot SWT is a continuously running block tunnel. That is, the nozzles which are used to achieve supersonic flow conditions are replaceable, fixed geometry blocks. For this investigation, the facility had a Mach number range of 1.3 to 4.0. Wind tunnel total pressures could range between 1 and 3 atmospheres which yielded unit Reynolds numbers from 12.0 to $24.0 \times 10^{6}$ per meter. The test section cross-plane dimensions are $30.5 \mathrm{x}$ $31.0 \mathrm{~cm}$. A schematic of the facility is shown in Fig. 3.

A flat plate that traversed the entire test section height was designed for the experiment. The plate was mounted at the spanwise centerline of the test section. Care was taken to mount the plate at a zero degree angle of attack relative to the tunnel freestream flow so no shock wave would be generated in the test area.

A schematic of the flat plate model is shown in Fig. 4. At an axial distance of $5.08 \mathrm{~cm}$ from the leading edge and symmetric about the model centerline, a $12.70 \mathrm{~cm} \mathrm{x}$ $17.78 \mathrm{~cm}$ section of the aluminum plate was milled out to install a proofboard insert. The proofboard material is used to insulate the model heat transfer measurement area from 


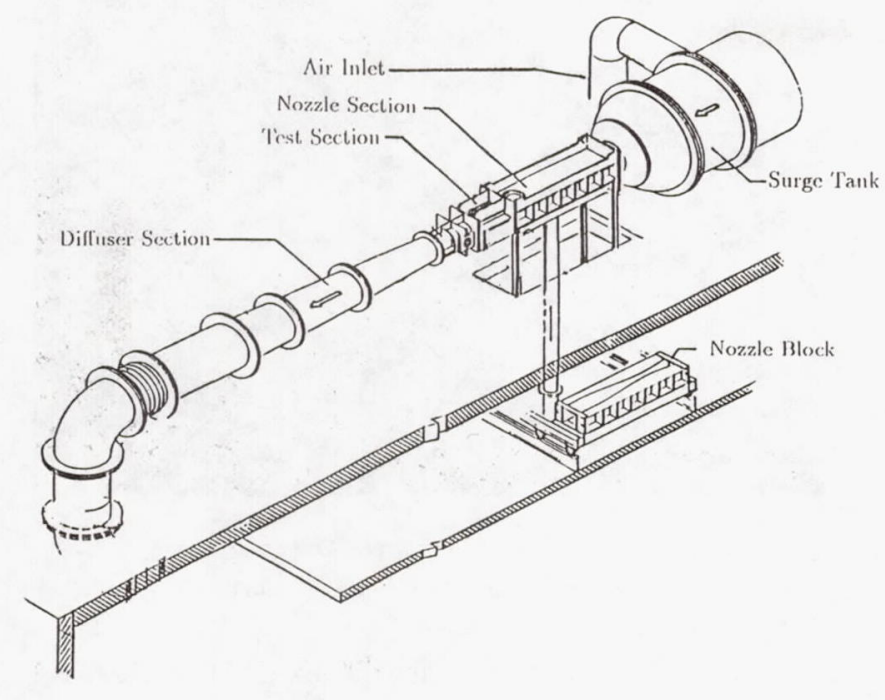

Figure 3. Schematic of NASA Lewis 1x1 Foot Supersonic Wind Tunnel

the plate aluminum material. This technique minimizes transient heat transfer conduction effects and allows the test surface to cool to the adiabatic wall temperature almost instantaneously. Peake et al. [4] used a similar insulation method in an experiment conducted to detect boundary layer transition with infrared thermography in a Mach 3.85 flowfield. The plate is then coated with a nominally $1 \mathrm{~mm}$ thick gel-coat resin to insure uniformity of the flow surface. This coating is painted flat black to enhance its emissivity for the infrared camera measurements.

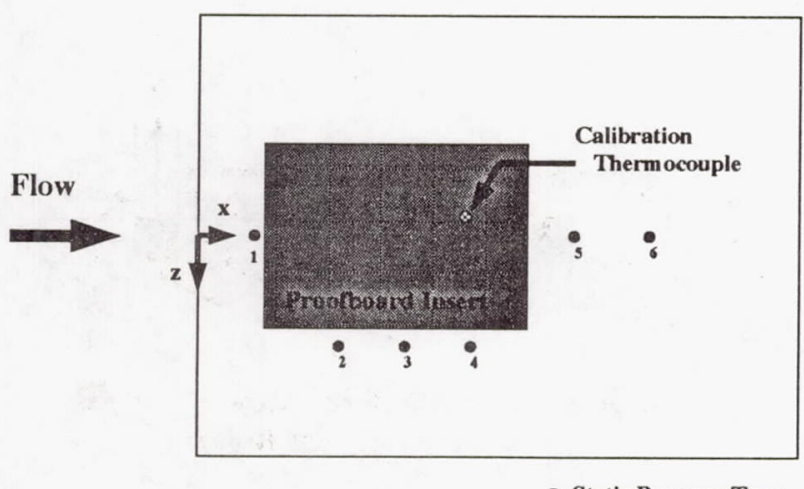

- Static Pressure Taps

Figure 4. Schematic of Flat Plate Model

\section{Experimental Method}

The approach taken in this investigation to verify the LIHF concept was to use the system to determine the local convective heat transfer coefficient on a flat plate in a supersonic flowfield at discrete points in a streamwise (axial) survey near the flat plate centerline. All measurements were made on the proofboard surface since it acts as an insulator to minimize transverse heat conduction effects.

The infrared camera system's radiation level output was calibrated versus known reference temperatures in the wind tunnel while operating at the actual test conditions. This procedure yielded temperature calibration curves at each test condition that were used for the subsequent data analysis. This calibration approach minimized indicated surface temperature errors due to measurement anomalies such as infrared transmission losses through the zinc sulfide window.

The net laser power available at the model surface was also determined by a calibration process. This was necessary because of transmission losses encountered as the beam passed through the zinc sulfide window and due to the manner in which the laser power was monitored in the system setup. As discussed earlier, the LIHF system used a laser power meter to monitor the the reflected laser beam from the attenuator/beamsplitter assembly during the test runs. Before each series of test runs, an additional power meter was placed in the wind tunnel test section to monitor the transmitted test laser power after it passed through the zinc sulfide window. The variation of the transmitted power versus the reflected power was noted, and the results were used as to generate a calibration curve of the measured reflected power versus the transmitted test laser power applied to the model surface.

After calibrating the LIHF system, the wind tunnel was brought on-line and set to a particular test condition. The Mach number was chosen by using one of the removable facility nozzle blocks. The infrared camera system was used to determine the operating unit Reynolds number since Peake et al. [4] previously demonstrated that an infrared camera could be used to detect boundary layer transition in a high speed, compressible flow. The infrared camera system monitored the flat plate surface temperature distribution over the entire proofboard surface, and the wind tunnel plenum pressure was adjusted until the transition region could be seen on the test surface.

When beginning an actual survey, the LIHF system was moved to the farthest downstream axial location on the survey line. The infrared camera lens zoomed in to focus on as small a viewing area as possible since the heated area on the plate was on the order of $10 \mathrm{~mm}$. The test laser power was adjusted to a constant level with the attenuator/beamsplitter assembly while the shutter in the 
transmitting optics was closed in order to prevent surface heating. The test laser power remained constant during the entire survey. When the survey began, the shutter was opened and the laser beam heated the test surface spot for approximately 10 seconds. During this time, the infrared camera system recorded the entire heating process on a video tape for future data reduction. At the end of the heating interval, the shutter was closed to prevent further surface heating, and the LIHF system moved $5 \mathrm{~mm}$ to the next upstream axial location in the survey line. This process was repeated until the completion of the axial survey.

\section{Heat Transfer Analysis}

In order to quantify the convective heat transfer process, a convective heat transfer coefficient is defined which relates the surface heat flux to a temperature potential difference. For supersonic flows, the convective heat transfer relation becomes

$$
q_{o}^{\prime \prime}=h\left(T-T_{a w}\right),
$$

where $q_{o}^{\prime \prime}$ is the wall heat flux, $\mathrm{h}$ is the convective heat transfer coefficient, $T_{a w}$ is the adiabatic wall temperature, and $\mathrm{T}$ is the local wall temperature. A significant thermal boundary layer exists by virtue of the temperature gradient between the freestream flow static temperature and flow surface adiabatic wall temperature.

For this study, one must understand the physical processes that are occurring with both the measurement technique and the aerodynamic heat transfer in order to determine the heat transfer characteristics of the flat plate in supersonic flow. A knowledge of the physical processes involved allows one to construct an analytical model to determine the local convective heat transfer coefficient. In this case, the laser beam induces a local flux that heats the model surface. The heating causes radial heat conduction in the model gel-coat resin which was used to give the flat plate a uniform surface finish. In addition to the heat conduction, convective heat transfer due to the fluid flow tends to cool the heated area. A typical infrared thermogram of the area affected by the laser heating is shown in Fig. 5 .

It was observed that as soon as the heat flux was applied, the local heated region would grow very rapidly, but after approximately 10 seconds, the heated area would come to an equilibrium state in which the spot size would remain constant with little surface temperature change. During the transient time period, the heated area diameter grows from the initial laser beam diameter of $1.3 \mathrm{~mm}$ to a steady-state diameter about 10 times as large. The rapid radial heat conduction tends to balance the heat flux. Convective heat transfer occurs during the entire

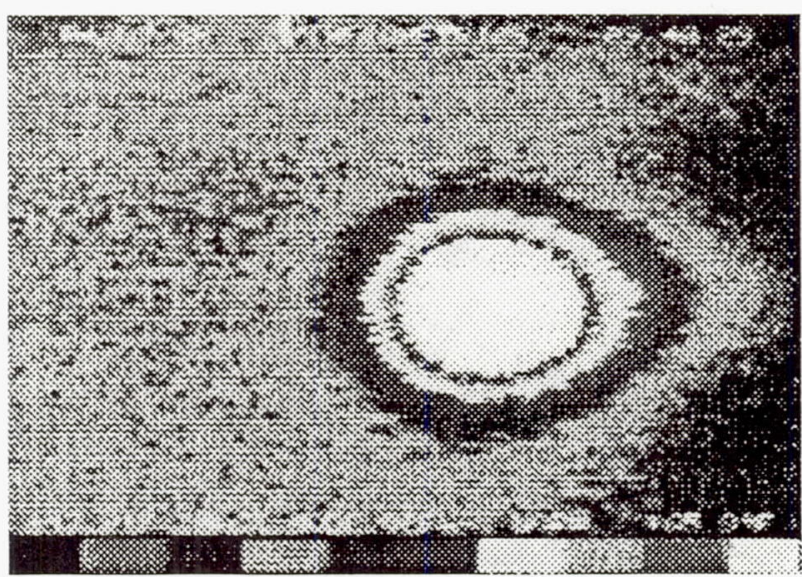

Figure 5. Typical Infrared Thermogram of Laser-Heated Area on Test Surface

process and also helps to balance the applied heat flux. An equilibrium or steady-state condition is reached when both the heat conduction and convection balances the applied heat flux.

The analysis used to determine the local convective heat transfer coefficient is performed at the steady-state condition, i.e., when the applied heat flux is balanced by the radial heat conduction and convection. The analytical method used in this study is similar to one used by Schneider [5] for heat transfer with convection in a nonadiabatic plate with a local heat source. In the present study, the gel-coat resin coating on the insulated portion of the flat plate is the test surface where the heat flux (source) is applied. Therefore, one side of the material is insulated, and convection occurs only at the flow surface. Figure 6 shows a schematic of the test surface used for the analysis.

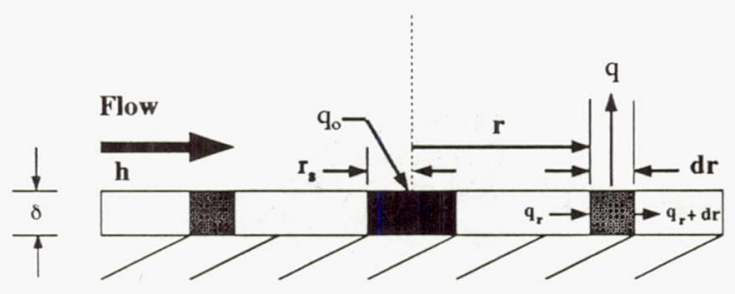

Figure 6. Cross-Sectional View of Flow Surface Measurement Region

Referring to Fig. 6, a source of strength $\mathrm{q}_{\mathrm{o}}$ and radius $r_{s}$ heats the gel-coat resin of thickness $\delta$. Before the heat flux is applied, the test surface temperature is near the adiabatic wall temperature. An energy balance at a radial distance $r$ from the center of the source at the steady state condition yields the following differential equation that 
describes the steady-state heat transfer process due to the applied heat flux on the flat plate model surface,

$$
\frac{d^{2} T}{d r^{2}}+\frac{1}{r} \frac{d T}{d r}-\frac{h}{k \delta}\left(T-T_{a w}\right)=0 .
$$

Now, defining a new variable, $\theta=T-T_{a w}$, the equation can be rewritten as follows,

$$
r^{2} \frac{d^{2} \theta}{d r^{2}}+r \frac{d \theta}{d r}-r^{2} \frac{h}{k \delta} \theta=0,
$$

which is recognized as a modified Bessel's equation with the following solution,

$$
\theta=C_{1} I_{o}\left(\sqrt{\frac{h}{k \delta}} r\right)+C_{2} K_{o}\left(\sqrt{\frac{h}{k \delta}} r\right)
$$

$\mathrm{I}_{\mathrm{o}}$ is a modified Bessel function of the first kind, of order 0 , and $\mathrm{K}_{\mathrm{o}}$ is a modified Bessel function of the second kind, of order 0 . The requirement that the solution to remain finite as $r \rightarrow \infty$ requires that $\mathrm{C}_{1}=0$ so,

$$
\theta=C_{2} K_{o}\left(\sqrt{\frac{h}{k \delta}} r\right) \text {. }
$$

Applying the steady state heat conduction relationship at the location of the applied heat flux,

$$
q_{o}=-k A_{r_{s}}\left(\frac{d T}{d r}\right)_{r=r_{s}},
$$

the constant, $\mathrm{C}_{2}$ is obtained. The resulting analytical temperature solution becomes

$$
T(r)=T_{a w}+\frac{q_{o}}{2 \pi \sqrt{h k \delta} r_{s}} \frac{K_{o}\left(\sqrt{\frac{h}{k \delta}} r\right)}{K_{1}\left(\sqrt{\frac{h}{k \delta}} r_{s}\right)},
$$

for $r>r_{s}$. In this expression, $\mathrm{k}$ is the thermal conductivity of the material, $\mathrm{h}$ is the convective heat transfer coefficient, and $\mathrm{K}_{\mathrm{o}}$ and $\mathrm{K}_{1}$ are modified Bessel functions of the second kind of order 0 and 1 , respectively.

Equation 7 yields an expression for the local steadystate temperature distribution on the flat plate due to the applied heat flux from the laser beam. All quantities are known except for the convective heat transfer coefficient, h. The experimental spot temperature distribution, $T(r)$, is known from the infrared camera system measurements. Therefore, the heat transfer coefficient term in the equation can be varied until the analytical solution matches the experimental data. Using this approach, the local heat transfer coefficient for a discrete point on the flat plate is determined. No attempt has been made to correct the derived convective heat transfer coefficients for radiation effects.

\section{Experimental Convective Heat Transfer Coefficients and Comparison with Theory}

The results presented here are the experimental heat transfer measurements for supersonic flow over a flat plate. The local convective heat transfer coefficients are obtained by using both the LIHF technique and analysis discussed in this investigation. Comparison of the data are made to laminar flow boundary layer theory developed by Van Driest [6] as presented by Kays [7].

The theory solves the momentum and energy equation for a high speed laminar boundary layer with variable properties. A Prandtl number of 0.75 is assumed, and a solution in the form of $S t \sqrt{R e_{x}}=f\left(M, T_{w} / T_{s}\right)$ is obtained. With the Mach number external to the flat plate and the wall temperature ratio known, the theoretical local convective heat transfer coefficient can be found. This procedure was applied and these results are presented with the experimental data.

In the analysis of the experimental data, a constant laminar recovery factor of 0.85 was used to calculate the flat plate adiabatic wall temperature throughout the entire flowfield. This assumes a Prandtl number of 0.72 . The theoretical analysis, however, assumes a Prandtl number of 0.75 , so a slight mismatch may occur when comparing the experimental results to the theoretical analysis.

Also, as noted earlier, a portion of the flow is transitional, so both the theory and experimental results are not strictly correct in this region. The theoretical analysis assumes laminar flow only and does not consider transition. The derived experimental convective heat transfer coefficients do not take into account the variation of wall recovery factor in the transition region and, hence, the adiabatic wall temperature. An unsuccessful attempt was made to determine the variation in wall recovery factor in the boundary layer transition region.

Surface static pressures on the flat plate were monitored during the data acquisition process. These measurements [8] indicate that the flat plate boundary layers were relatively well-behaved with no evidence of flow separation present.

The experimentally-determined convective heat transfer coefficients and comparison with the theory are shown in Figs. 7-10. In general, the experimental heat transfer coefficients are higher than theoretical predictions. Some of this discrepancy could be attributed to the data reduction approach which depends on a precise knowledge of the gelcoat thermal conductivity. Unfortunately, the manufacturer of the gel-coat resin used in this investigation (REN 1129 by Ciba-Geigy) has never determined the thermal conductivity of this material. Therefore, a value of the thermal conductivity was assumed based on published values of 
similar materials. This value could be off by as much as a factor of two. There is also the possibility that the applied heat flux was significant enough to change the flow surface condition to an unheated starting length boundary condition rather than a constant temperature boundary condition which would result in experimental heat transfer coefficients being higher than the theoretical predictions. Also, the limitation of the infrared camera system's ability to resolve the heated area surface temperature distribution yields a \pm 10 percent uncertainty of the convective heat transfer coefficients [8].

For all test cases, the flat plate boundary layer begins to transition in the measurement region, and transition proceeds to the end of the measurement region without the flow becoming fully turbulent. The approximate locations of the onset of transition were determined and are shown in Figs. 8 and 9 for the Mach 3.0 and 3.5 cases, respectively. For the Mach 2.5 and 4.0 conditions, Figs. 7 and 10, the location of the onset of transition was not determined.

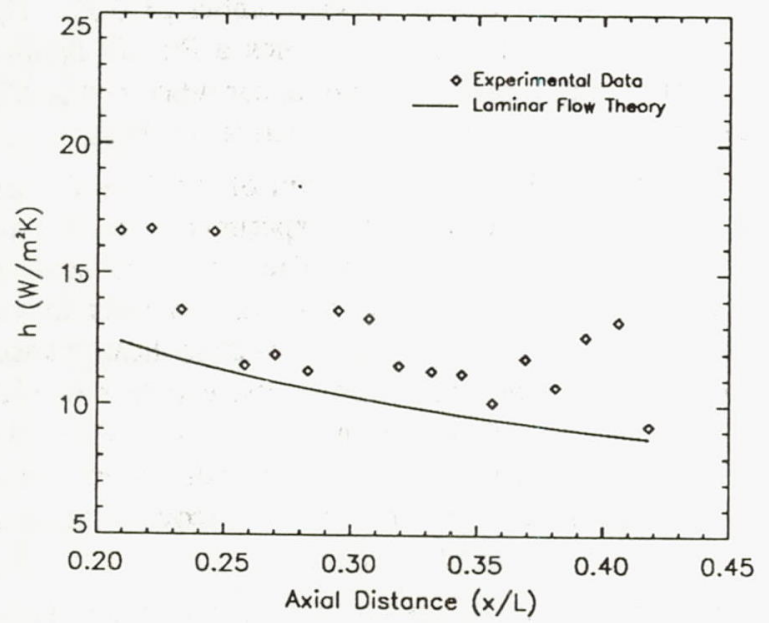

Figure 7. Flat Plate Convective Heat Transfer Coefficient Distribution, $M_{\infty}=2.5$

At the Mach 2.5 condition, the experimentallydetermined heat transfer coefficients shown in Fig. 7 generally follow the trend of the laminar flow theory, but the experimental values are higher than predicted, and there are some scatter in the data. Some of the data scatter are attributed to measurement uncertainties caused by limitations in the PC based data reduction system's ability to resolve the infrared thermal images.

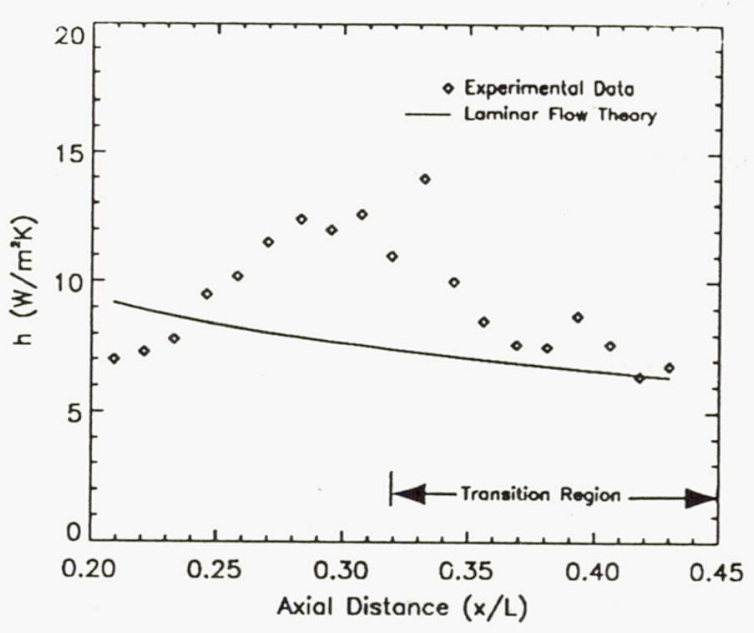

Figure 8. Flat Plate Convective Heat Transfer Coefficient Distribution, $M_{\infty}=3.0$

For the Mach 3.0 results shown in Fig. 8, there are less scatter in the experimental data. At the beginning of the measurement region, the experimental results show heat transfer coefficients lower than what the theory predicts that gradually recover to overshoot the theoretical predictions. It appears that this is a gradient region in which the flow is adjusting to some disturbance. Next, a region exists where the experimental convective heat transfer coefficients appear to have reached a plateau and are relatively constant when compared to the trend in the theoretical values. Then comes the onset of transition in which the experimental convective heat transfer coefficients take a step change downward.

The Mach 3.5 heat transfer results presented in Fig. 9 show significant data scatter upstream of the transition location. The data scatter in this region are attributed to problems in the data acquisition process at this condition. During the data reduction process, it was observed that the time duration of the applied heat flux was not long enough to allow the heated region to stabilize to a steady state local surface temperature distribution. The analysis used to determine the convective heat transfer coefficient based on the surface temperature distribution is a steady state analysis so the experimental results upstream of the transition location are questionable. 


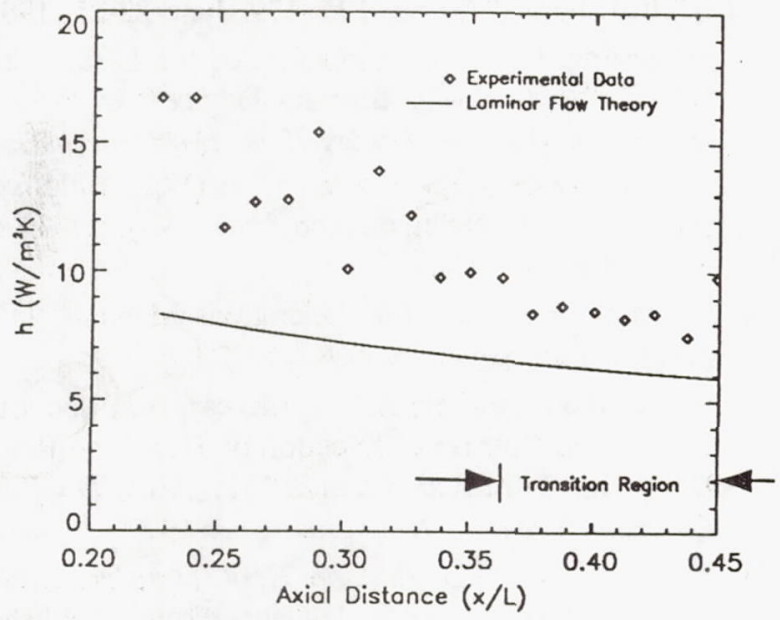

Figure 9. Flat Plate Convective Heat Transfer Coefficient Distribution, $M_{\infty}=3.5$

In the transition region, the Mach 3.5 experimentallydetermined convective heat transfer coefficient distribution becomes well behaved and settles out to values higher than are expected for a laminar boundary laver. Again, the experimental results assume a constant laminar recovery factor in this region. In reality, the recovery factor does vary in the transition region, so the experimentally-determined convective heat transfer coefficients presented here are not accurate.

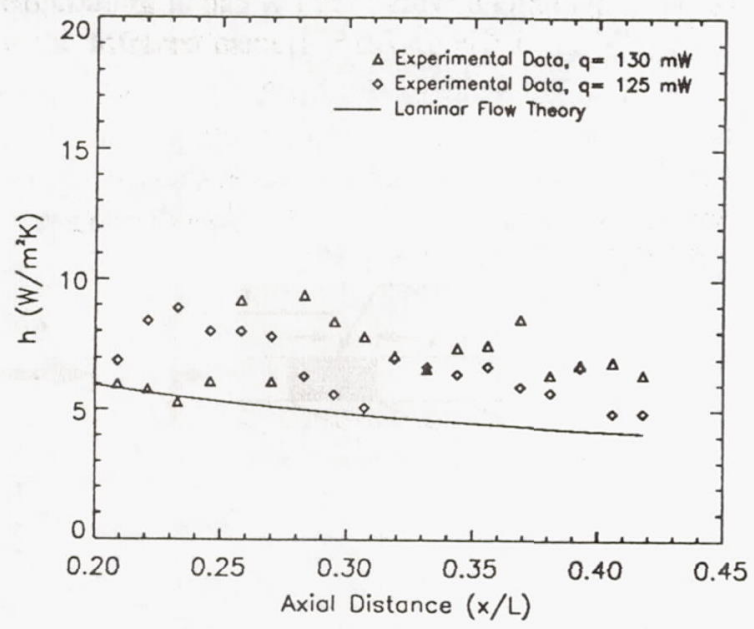

Figure 10. Flat Plate Convective Heat Transfer Coefficient Distribution, $M_{\infty}=4.0$

The Mach 4.0 results are shown in Fig. 10. At this condition two separate surveys were conducted at different applied laser heat flux power levels. Both results indicate higher heat transfer than the theoretical laminar flow predictions, and there is more data scatter for the higher applied heat flux power case. This data scatter could be a result of the heated areas not coming to a steady state condition in the allotted time interval during the data acquisition process.

If one considers the fact that these heat transfer measurements were made to demonstrate the feasibility of a new measurement technique, the results presented here are reasonable. In Ref. [9] Kaufman II and Johnson present convective heat transfer measurements for undisturbed laminar boundary layers at Mach 8 and unit Reynolds numbers of 2 to 6 million per meter. They measured convective heat transfer coefficients in the range of 2.0 to $8.5 \mathrm{~W} / \mathrm{m}^{2} \mathrm{~K}$ over the range of Reynolds numbers in the study. The present investigation was conducted at similar Reynolds numbers, but at lower Mach numbers. The experimental convective heat transfer coefficients presented in this investigation are in the same range measured by Kaufman II and Johnson.

Gulbran et al. [10] presented convective heat transfer measurements for an undisturbed laminar boundary layer at Mach numbers of 6, 8, and 10 at a unit Reynolds number of 3.2 million per meter. They measured convective heat transfer coefficients of 1.2 to $3.0 \mathrm{~W} / \mathrm{m}^{2} \mathrm{~K}$ which are slightly lower than the values seen in the present study. This is expected since the experiments of Gulbran et al. were conducted at higher Mach numbers and a lower Reynolds number. The measured convective heat transfer coefficient distributions presented by Gulbran et al. for the undisturbed laminar boundary layers do show data scatter similar to what was seen in the present study. In their experiments, the worsi data scatter was seen at the Mach 6.0 condition where a 50 percent difference in convective heat transfer coefficients was observed at adjacent measurement locations. This is an indication that precise measurements of convective heat transfer in an undisturbed laminar boundary layer are difficult to make.

\section{Concluding Remarks}

An investigation has been conducted to develop an instrumentation system capable of high resolution surface heat transfer measurements in complex, three-dimensional high speed flows. The concept conceived in this study to make these heat transfer measurements is a laser-induced heat flux technique (LIHF) which uses a laser to induce a local heat flux at a point on a model surface. During the application of the heat flux, an infrared camera system monitors the surface temperature distribution, and a local convective heat transfer coefficient is determined by an analysis of the area affected by the local heating. 
In order to assess the feasibility of this concept, the LIHF technique was used to make surface convective heat transfer measurements for flat plate transitional boundary layers in high speed flows. The experiments were conducted over a nominal Mach number range of 2.5 to 4.0. These measurements were presented and compared to theoretical convective heat transfer coefficient distributions for high speed laminar boundary layers. The results compared reasonably well with theory, but some scatter in the experimental data was observed. Some of the data scatter was attributed to minor problems in the data acquisition process. Also, because of the approach used for the temperature calibration of the infrared camera system, the variation in adiabatic wall temperature recovery factor could not be determined, and the resulting convective heat transfer coefficients determined for the transitional portion of the flat plate boundary layers were not accurate.

Overall, the results of this investigation indicate that the LIHF concept could be a viable surface convective heat transfer measurement technique. Future studies will use the LIHF technique to make heat transfer measurements in complex, three-dimensional high speed flows, specifically shock wave/turbulent boundary layer interaction studies. However, in order to make more accurate convective heat transfer measurements, an improved temperature calibration approach must be developed for the infrared camera system so that local changes in the model adiabatic wall temperatures can be resolved.

\section{References}

[1] Heath, D.M., Winfree, W.P., Carraway, D.L., and Heyman, J.S., "Remote Noncontacting Measurements of Heat Transfer Coefficients for Detection of Boundary Layer Transition in Wind Tunnel Tests," in
ICIASF '87, (The College of William and Mary, Williamsburg, VA), pp. 135-139, June 22-25, 1987.

[2] Stinebring, D.R., "Development of the Liquid Crystal/Skin Friction Measurement Device," in Flow Visualization III: Proceedings of the Third International Symposium on Flow Visualization (W.J. Yang, ed.), (University of Michigan, Ann Arbor, MI), pp. 49-54, September 6-9, 1983.

[3] "Inframetrics Model 600 Operations Manual." Inframetrics, Inc., Billerica, MA.

[4] Peake, D.J., Bowker, A.J., Lockyear, S.J., and Ellis, F.A., "Non-Obtrusive Detection of Transition Region Using an Infra-Red Camera," in AGARD-CP-224 Laminar-Turbulent Transition, May 1977.

[5] Schneider, P.J., Conduction Heat Transfer. Second printing, Reading, MA: Addison-Wesley Publishing Company, Inc., September 1957.

[6] Van Driest, E.R., "Investigation of Laminar Boundary Layer in Compressible Fluids Using the Crocco Method." NACA TN-2597, January 1952.

[7] Kays, W.M. and Crawford, M.E., Convective Heat and Mass Transfer. New York, NY: McGraw-Hill Book Company, 1980.

[8] Porro, A. R., Keith Jr, T. G., Hingst, W. R., Chriss, R. M., and Seablom, K. D., "Development of a LaserInduced Heat Flux Technique for Measurement of Convective Heat Transfer Coefficients in a Supersonic Flowfield." NASA TM 103778, March 1991.

[9] Kaufman II, L.G. and Johnson, C.B., "Weak Incident Shock Interactions with Mach 8 Laminar Boundary Layers." NASA TN D-7835, December 1974.

[10] Gulbran, C.E., Redeker, E., Miller, D.S., and Strack, S.L., "Heating in Regions of Interfering Flow Fields, Part III: Two-Dimensional Interacion Caused by Plane Shocks Impinging on Flat Plate Boundary Layers." AFFDL-TR-65-49, March 1967. 
Public reporting burden for this collection of information is estimated to average 1 hour per response, including the time for reviewing instructions, searching existing data sources gathering and maintaining the data needed, and completing and reviewing the collection of information. Send comments regarding this burden estimate or any other aspect of this Davis Highway, Suite 1204, Arlington, VA 22202-4302, and to the Office of Management and Bud Jerices, Dir

AGENCY USE ONLY (Leave blank)

\begin{tabular}{r|l|l} 
1. AGENCY USE ONLY (Leave blank) & 2. REPORT DATE & $\begin{array}{r}\text { 3. REPORT TYPE AND DATES COVERED } \\
\text { Technical Memorandum }\end{array}$ \\
\hline
\end{tabular}

4. TITLE AND SUBTITLE

5. FUNDING NUMBERS

A Laser-Induced Heat Flux Technique for Convective Heat Transfer

Measurements in High Speed Flows

6. AUTHOR(S)

WU-505-62-52

A.R. Porro, T.G. Keith, Jr., and W.R. Hingst

7. PERFORMING ORGANIZATION NAME(S) AND ADDRESS(ES)

8. PERFORMING ORGANIZATION REPORT NUMBER

National Aeronautics and Space Administration

Lewis Research Center

Cleveland, Ohio 44135-3191

E- 6473

9. SPONSORING/MONITORING AGENCY NAMES(S) AND ADDRESS(ES)

10. SPONSORING/MONITORING AGENCY REPORT NUMBER

National Aeronautics and Space Administration

Washington, D.C. 20546-0001

NASA TM-105177

11. SUPPLEMENTARY NOTES

Prepared for the 14th International Congress on Instrumentation in Aerospace Simulation Facilities sponsored by the IEEE Aerospace and Electronics Systems Society, Rockville, Maryland, October 27-31, 1991. A.R. Porro, and W.R. Hingst, NASA Lewis Research Center. T.G. Keith, Jr., Ohio Aerospace Institute, 2001 Aerospace Parkway, Brook Park, Ohio 44142, and University of Toledo, Department of Mechanical Engineering, Toledo, Ohio 43606. Responsible person, A.R. Porro, (216) 433-5921.

12a. DISTRIBUTION/AVAILABILITY STATEMENT

Unclassified - Unlimited

Subject Category 34

13. ABSTRACT (Maximum 200 words)

In this study, a technique is developed to measure the local convective heat transfer coefficient on a model surface in a supersonic flowfield. The technique uses a laser to apply a discrete local heat flux at the model test surface, and an infrared camera system determines the local temperature distribution due to the heating. From this temperature distribution and an analysis of the heating process, a local convective heat transfer coefficient is determined. The technique was used to measure the local surface convective heat transfer coefficient distribution on a flat plate at nominal Mach numbers of 2.5, 3.0, 3.5, and 4.0. The flat plate boundary layer initially was laminar and became transitional in the measurement region. The experimentally-determined convective heat transfer coefficients were generally higher than the theoretical predictions for flat plate laminar boundary layers. However, the results indicate that this non-intrusive optical measurement technique has the potential to measure surface convective heat transfer coefficients in high speed flowfields.

14. SUBJECT TERMS

Fluid flow; Heat transfer; Boundary layers

17. SECURITY CLASSIFICATION OF REPORT

Unclassified
18. SECURITY CLASSIFICATION OF THIS PAGE Unclassified
19. SECURITY CLASSIFICATION OF ABSTRACT

Unclassified 